\title{
Estudo de usabilidade entre aplicações nativas e multiplataforma no sistema Android
}

\author{
Léo Altíssimo Neto, Sérgio S. S. Filho, Dárley D. de Almeida \\ Departamento de Ciência da Computação \\ Universidade do Estado de Mato Grosso (UNEMAT) - Alto Araguaia, MT - Brasil \\ \{ leo.altissimo@unemat.br, santos@unemat.br, darleydalmeida@gmail.com
}

\begin{abstract}
This study report the investigation of a possible user experience quality lost on mobile applications when compar a application developed of native approach, with respect to a developed a cross-platform approach. To make this study, are madeded two applications with identical appearance and functional structure. one following a native approach and the other using a cross-platform framework. In this paper is be presented the development processes of the two applications and the challenges founded on this process.
\end{abstract}

Resumo. Este estudo relata a investigação da possível perda na qualidade de usabilidade em aplicações móveis quando comparado uma aplicação desenvolvida de forma inteiramente nativa, com relação a uma desenvolvida através de uma abordagem cross-plataform. Para desenvolver o estudo, foram criadas duas aplicações de aparência e estrutura de funcionamento idênticas, uma seguindo a abordagem nativa e outra utilizando um framework cross-plataform. Neste trabalho será apresentado o processo de desenvolvimentos das aplicações e os desafios encontrados no decorrer deste processo.

\section{Introdução}

Com o enorme engajamento dos smartphones na sociedade moderna, surge um novo mercado, o de aplicativos. O número de aplicações móveis existentes cresce constantemente, já existindo certa de 2.7 milhões [Statista 2019] de aplicações disponíveis, e cerca de 6140 [Statista, 2018] novas aplicações são adicionados diariamente na Play Store, loja oficial do sistema mobile mais usado, o Android. Segundo [Glauber, 2014] entre os anos de 2013 e 2014 mais de 5 bilhões de dólares foram distribuídos entre os desenvolvedores de aplicações móveis.

Com os usuários de smartphones distribuídos entre diversos sistemas operacionais independentes. Empresas e desenvolvedores que tenham a intenção de alcançar todo o mercado de usuários de smartphones, devem disponibilizar uma versão de sua aplicação específica para cada sistema operacional [Heitkötter et al. 2013]. Como alternativa a esta prática, surgiu a abordagem do desenvolvimento de aplicações móveis cross-platform, que tem por conceito produzir apenas um código fonte e ser capaz de gerar aplicações para diversas plataformas [Cevallos, 2014]. Contudo o uso destes frameworks podem gerar pontos negativos com relação a performance. 
O objetivo do trabalho é investigar as possíveis perdas de na qualidade da experiência do usuário decorrentes do uso de técnicas de desenvolvimento multi plataforma. Pois performance é essencial um uma boa experiência do usuário que consequentemente é importante para o engajamento do cliente no uso da aplicação e no sucesso do produto. [Cevallos, 2014].

\section{Metodologia}

O desenvolvimento deste trabalho se inicializou com o estudo de desenvolvimento de aplicações móveis para o sistema Android. Logo após foi realizado o estudo acerca do desenvolvimento móvel cross-plataform. E definido que seria usado o React Native, um framework em JavaScript que dentre outras as opções era o que apresentava resultados mais próximos da aplicação nativa.

Com o estudo necessário para abordagem do problema concluído, foi definido qual seria o conceito da aplicação. Foi levando em consideração funcionalidades, transições, recursos de hardware e serviços amplamente utilizados por usuários de smartphones atualmente. Chegou-se então ao projeto de uma aplicação para troca de mensagens rápidas em tempo real com outros usuários. É relativamente simples, porém funcional e aplica todos os pontos necessários para realizar o estudo.

A etapa final do trabalho ainda está em andamento, que serão os testes em laboratório de performance e execução e o testes com usuários reais utilizando sem ter o conhecimento de qual versão estão utilizando e responderem um questionário acerca da usabilidade, fluidez e pontos relevantes sobre a experiência de ter usando tais aplicativos.

\section{Resultados e Discussões}

De fato, ao realizar o desenvolvimento de ambas as aplicações, nota-se que partindo de uma visão do desenvolvedor que busca velocidade e facilidade de desenvolvimento e portabilidade para diversas plataformas, o uso de um framework cross-platform é justificado e apresenta diversos benefícios em relação ao desenvolvimento nativo de uma aplicação. Contudo garantir que o usuário tenha a melhor UX possível é importante para o sucesso do produto.

Um exemplo que demonstra que é mais fácil e dinâmico desenvolver com React Native em relação à aplicação Nativa, foi a criação do campo de texto do login que possui bordas arredondadas. Com React Native para conseguir este resultado basta apenas configurar uma propriedade para aquele componente, já na abordagem nativa, é necessário criar um arquivo de configuração no formato XML, para aplicar essa propriedade, então somente configurar esse XML como sendo o background da caixa de texto. Este é apenas um exemplo, contudo diversos outros detalhes levaram a concluir que o desenvolvimento cross-platform tem potencial para ser consideravelmente mais prático e dinâmico.

Com relação ao estudo de UX, os pontos foram levantado como alvo de estudo e demandaram atenção e foco nos testes foram a performance e a fluidez no uso das aplicações. Pois tanto esteticamente quanto em relação à usabilidade, as duas aplicações chegaram exatamente ao mesmo resultado, a ponto de não ser possível diferenciá-las caso já não saiba previamente. Como exemplo, pode-se observar na Figura 1, que as telas de ambos aplicativos para um mesmo cenário de uso, são bastante semelhantes. 

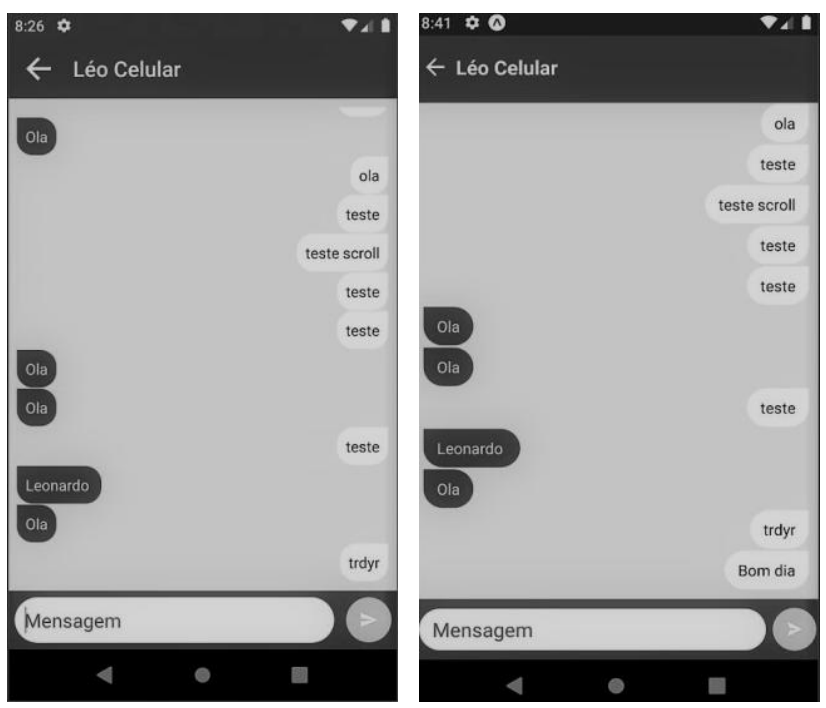

Figura 1. A esquerda o Mensageiro desenvolvido de forma nativa e na direita o mesmo aplicativo em versão desenvolvida com uso do framework React Native.

\section{Considerações Finais}

Este trabalho contribui para estudos a respeito de usabilidade em dispositivos móveis, além de ser uma fonte de consulta para empresas ou desenvolvedores que necessitarem decidir qual abordagem de desenvolvimento escolher para projetos futuros.

Apesar de ainda não termos resultados oficiais sobre o estudo, o uso durante o desenvolvimento e em testes informais já revelam resultados animadores com relação ao uso deste tipo de framework, pois além de visualmente muito semelhantes, com relação a performance também não notou-se gargalos durante o seu uso.

\section{Referências}

Statista, (2019), "Number of available applications in the Google Play Store from December 2009 to June 2019." https://www.statista.com/statistics/266210/number-of-available-applicationsin-the-google-play-store/, Agosto.

Statista, (2018), “ Smartphone Addiction Tightens Its Global Grip.” https://www.statista.com/chart/9539/smartphone-addiction-tightens-its-global-grip/, Agosto.

Glauber N. (2015) “Dominando o Android: Do básico ao Avançado”, 2a ed. São Paulo: Novatec.

Heitkotter, H.; Hanschke, S.; Majchrzak, T. A (2013) "Evaluating cross-platform development approaches for mobile applications", Web Information Systems and Technologies, http://link.springer.com/chapter/10.1007/978-3-642-36608-6_8, Agosto.

Cevallos, E. A, (2014) “Case Study on Mobile Applications UX: Effect of the Usage of a Cross Platform Development Framework", Madrid, Universidad Politécnica de Madrid, http://oa.upm.es/ 30422/1/EMSE-2014-05_Esteban_Angulo-1.pdf, Agosto. 